\title{
Culture Implications on Future Work Design - New Technologies and Collaborations for Controllers and Pilots
}

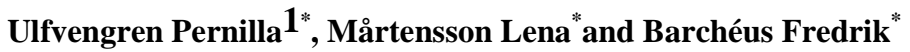 \\ ${ }^{*}$ KTH, Royal Institute of Technology \\ Div of Industrial Work Science \\ School of Industrial Technology and Management \\ Lindstedtsvägen 30 \\ S-100 44 Stockholm, Sweden \\ pernilla.ulfvengren@indek.kth.se
}

\begin{abstract}
As Air Traffic Control, ATC, has evolved gradually during the 20th century technology, law and culture have been developed and introduced into aviation in such a way that the aviation community in Europe now appears like a patchwork consisting of virtually hundreds of different and fragmented parts. Current harmonisation work such as the European Single Sky initiative may be seen as a reaction to this (European Commission, 1999). In the decade to come aeronautics will face large challenges when capacity limits will be reached because of ever increasing traffic. New technology is now gradually being introduced in order to meet these challenges (Eurocontrol,1998). In future aviation system pilots and air-traffic controllers will have new roles, responsibilities and ways of collaboration. The context for pilots and controllers work is very different, yet they are complementary actors in a common system. The two groups have different professional cultures and will be part of a common change. This paper consolidate recent research from Air Traffic Control, Flight Operations and Maintenance on issues such as organisational culture, safety culture, implementing major organisational change and a new human factors model. It is suggested that the consolidated research may be applied to and facilitate future changes in their joint system due to the many similarities and differences between flight operations (FO) and air traffic control (ATC) that exist. One conclusion is that the overall implication for future work design between controllers and pilots is not only cultural. It is necessary to develop theoretically sound practice that can create new organisational processes which are functionally effective for all stakeholders and which then provide the basis for a new collective understanding of how the system can work (McDonald, 2009) and go from there. Further research should be focused on discussing the re-
\end{abstract}

\footnotetext{
${ }^{1}$ Corresponding author
} 
levance for developing a common process model with training modules for crosslearning and develop a common reporting system to feed common risk models and performance measures.

\section{Introduction}

As Air Traffic Control, ATC, has evolved gradually during the $20^{\text {th }}$ century technology, law and culture have been developed and introduced into aviation in such a way that the aviation community in Europe now appears like a patchwork consisting of virtually hundreds of different and fragmented parts. Current harmonisation work such as the European Single Sky initiative may be seen as a reaction to this (European Commission, 1999). In the decade to come aeronautics will face large challenges when capacity limits will be reached because of ever increasing traffic. New technology is now gradually being introduced in order to meet these challenges (Eurocontrol,1998).

In future aviation system pilots and air-traffic controllers will have new roles, responsibilities and ways of collaboration (Barchéus and Mårtensson, 2003). New technologies will allow for pilots to control separation of aircraft. The context for pilots and controllers work is very different, yet they are complementary actors in a joint cognitive system (Hollnagel, 2007) with overlapping functional causal system. The two groups have different professional cultures.

The importance of culture has been acknowledged and is believed to have impact on an organisation's efficiency, safety and quality. For example analyzing organisational culture might identify perceptions on weaknesses in working conditions (Arvidsson, 2006) or enablers and barriers to implementing changes (DiasCabrera et al., 2009).

As of now there are approximately 60 Air Traffic Control Centers (ATCC) and with new technology and organisational structures many of these will possibly merge. Major consequence of a fusion will be the merger of workforces with different national conditions and this might bring organisational issues and safety culture into focus (Arvidsson, 2006). Related aspects have been studied in a merger of two airlines (Ulfvengren et al., 2009) which is an organizational change including two different and strong professional cultures in the same work domain.

An idea presented here is to discuss cultural implications on future change and possible increased collaboration between air and ground in the Aviation system in relation to knowledge from other areas on organisational culture, change and merges. An initial discussion on applying results from a recent Human Factors project called HILAS (McDonald, Ulfvengren and Ward, 2009), to this context, is presented. 


\section{Purpose}

The overall goal with this current research is to increase overall system performance and human well-being without compromising safety. The objective of this paper is to discuss cultural implications for future design of work, new technologies and collaborations for controllers and pilots. This discussion will be built on work:

- Reviewing recent research relevant to aviation systems such as; Human Factors (HF), cultural aspects on implementing changes and organisational culture.

- Identifying similarities and differences between flight operations (FO) and air traffic control (ATC) which may be of interest for designing and implementing increased collaboration and technologies for two work domains and professional cultures in a common system.

- Applying HF and inter-organisational culture aspects on the intraorganisational aspects between Flight operations and Air Traffic Control to facilitate future changes in their joint system.

\section{Method}

The content of this paper is an initial discussion, consolidating recent research and bring it into a new context. Our group at KTH has participated in HILAS doing mainly flight operations related work and earlier we have also conducted ATC research. We are a multidisciplinary Human Factors specialist group with engineers, psychologist and pilots. Our work is based on interviews and observations of pilots, controllers and personnel in airlines and air traffic management organizations at all levels.

\section{Theoretical framework}

For the last 30 years Human Factors (HF) has been expressed as the most critical discipline to improving aviation safety and HF remains the central area where verifiable progress has to be made if substantial gains in safety are to be achieved (McDonald, 2006). However, in relation to the amount of research not much human factors knowledge has shown to have been effectively implemented which actually puts the credibility of Human Factors on the line.

The Aviation Psychology Research Group at Trinity College in Ireland has for many years conducted excellent human factors research in the maintenance domain in the ADAMS, AMPOS, AITRAM and ADAMS-2 projects. A summary that accounts of much of this evidence can be found in McDonald, 1999, 2001; McDonald et al., 2000, as cited in McDonald (2009). They have identified some 
main phenomena which are not possible to explain by common theory or HF models: Double standard describing the gap between strategic management views of operations and the real "normal" operations as performed by operators, WIPIDO meaning Well Intended People In Dysfunctional Organisations and describes how operators do their best to overcome an actual or perceived lack of support in operations, a strong professional culture seams to compensate for weaknesses in the organisation and cycles of stability describes that even after failures organizations do not easily learn and change. It is believed that effects of these phenomena are haltering change and improvement of system. As an answer to this research a New Human Factors model has been suggested (McDonald, 2009). Four key theoretical themes; system, action, sense-making and culture are identified and combined into this model, believed to have both relevance and leverage in real life applications. "It is proposed that these terms represents or refer to different aspects of the same underlying reality...” (Mc Donald, 2009)

The research also resulted in more research acknowledging the importance of the operational processes enabling and supporting change and creating the necessary understanding of what needs to change and provide new channels of action to achieve that change. Creating a new understanding involves managing and integrating different type of knowledge, both tacit and explicit. Tacit knowledge from those who operates the system may include reasons for doing things in a certain way, even informal ways. This knowledge has to be reconciled with the deep "know-how" of Human Factors about the activity of people in socio-technical systems.

With this "research call” from the Trinity group, the HILAS project (Human Integration in the Lifecycle of Aviation Systems) (McDonald et al., 2009) was launched and run for four years. HILAS is a research and development initiative aiming at integrating Human Factors knowledge in the life cycle of aviation. This project came about to deal with the strategic issues in the design, operation and regulation of large integrated operational systems. The research within HILAS aims at developing new technologies as well as new operational and management concepts and processes including new capabilities to model operational systems. The project was initially divided into four strands: Flight operations, Maintenance, Flight deck technologies and Knowledge integration. The result is a theoretical and process framework for managing change, performance, risk and learning. An essential tool which supports most of these processes is the Operational

Process Model and Knowledge Space Model (OPM/KSM). These frameworks and tools are functionally effective for all stakeholders and provide the basis for a new collective understanding of how the system can work.

\section{Culture}

Culture is a problematic concept and just about every aspect of human life can be indicative of culture. This paper has a broad approach to the concept and has no 
ambition in clarifying distinctions of various cultures. In this paper culture is treated as a concept including various cultural aspects and subcultures which are considered relevant for organisational efficiency, safety and quality. Today the importance of organisational culture is clearly acknowledged in regulation (ICAO, 2008) by researchers and by practitioners such as airlines, maintenance organizations and air traffic controllers.

Very simple organisational culture may be described as extrinsic and concrete behavior as well as intrinsic and tacit meanings. People make sense of their whole situation they are in. Culture is therefore their reflection on the real system they encounter!

As mentioned earlier maintenance research has pointed at patters of action and culture that saves the day and compensate for perceived and actual organsiational deficiencies. Individual judgement and de-centralised decision for an effective outcome more important, for example avoid delays, than to follow standard procedures. This is closely linked of course to available time and resources to do a job safely and well (MC Donald, 2000).

When culture is not shared across or between organizations the mechanism for change is weak. Different views of the operations make it difficult to have a common view of what to change and understanding functionality of the system, what enables or constraints actions, is essential.

\section{Culture and implementation of major organisational change}

In research by Dias-Cabrera et al. (2009) requirements for successful implementation of a major organisational change are identified with purpose to improve safety through facilitating knowledge transformation and learning (Reason, 1997). The change in focus here is implementation of a socially-based or people driven knowledge management system (KMS). Many times socio-cultural aspects of evaluation processes and organisational change are often overlooked and fall mainly on technological aspects. Although IT-based activities are essential it is argued that "successful knowledge management depends on a suitable sociallybased or people-driven KMS”. A KMS is described to focus on improving knowledge creation among individuals in a group as well as at organisational level.

It is stated that the success of an implementation of a KMS depends on the existence of an organisational culture that facilitates intra-and inter-organisational coordination and information and communication processes. The research identifies organisational culture enablers and barriers and develops a HILAS Organisational Cultural Scale (H-OCS). The identified relevant cultural dimensions are (Diaz-Cabrera et al. 2009): 1) Organisational values (information permeability, approachability of management); 2) Organisational Practices and Policies ( twoway vertical interaction, participation); 3) Individual and Group Perceptions (shared values of work, organisation and change process); 4) Trust in manage- 
ment and organisation (credibility, justice); 5) Climate (foster motivation, job satisfaction). Examples of underlying issues are given in parenthesis.

Except for taking into account these dimensions when implementing organisational changes recommendations are also given to plan the change process by developing a: Dissemination plan (information about objective, recipients, meetings, distribution channels and media etc.); Organisational plan (Developing a shared vision about the change, foster workers participation in developing implementation plan, rewarding system etc.); Training program about KMS implementation (identifying knowledge and competence needs, evaluation of training program etc.); Change process success evaluation (evaluate and change accordingly for improvements).

Joint consideration of these dimensions and implementation plan is recommended to facilitate a successful implementation of a KMS in an organisation.

\section{Safety culture}

In his thesis Arvidsson (2006) states that since more and more people become involved in air traffic operations due to growth and fragmentation there will be increased demands on organizing and coordinating between people and procedures. He argues that therefore greater attention should be given to the psycho-

organisational aspects for example psycho social work environment and safety culture. However there are weaknesses to earlier research on this field for example there is limited empirical research that shows relationships between these psychoorganisational aspects and there is much ambiguity in defining and operationalizing the concept of safety culture. In a review, as cited in Arvidsson (ibid.), there were 16 definitions of safety culture and climate of which seven were safety culture. In a literature review (ibid.) important components reflecting a safety culture in an organisation are consolidated to organisational commitment, management involvement, employee empowerment, reward systems and reporting systems. Some psycho-social work environment aspects that have been identified in ATC to have potential effect on safety are social complications, interpersonal problems with co-workers and supervisors, organizational changes and lack of management support (ibid). Also Reason (1997) identified four aspects when stating that a safety culture was an informed culture if including; a reporting culture, a just culture, a flexible culture and a learning culture. In SAS annual report (SAS, 2009) key aspects are discussed for their positive safety culture being; communication based on mutual trust, a common perception of, or view on, the importance and role of safety work, having confidence in effectiveness in proactive measures taken, wellfunctioning reporting routines, a management committed to safety activities at all levels and strictly following their documented safety policies. 


\section{Organisational merger}

Within the HILAS project KTH's Human Factors group studied a merge of two airlines that started in 2000 (Ulfvengren et al. 2009 b). Within the newly developed airline, management acknowledged the importance of considering the culture from the two airlines as well as the feeling of uncertainty among the staff. Seminars were held and courses given in order to create a joint culture focusing on similarities between the two companies. These activities have taken place in parallel with ordinary operation. According to this study the personnel is the most important as a starting point, not the commercial issues.

It is therefore suggested that management should communicate the goals of the merger in a clear and understandable way to all employees. Create opportunities to brain storm the different processes in the airline with the personnel well in advance of the integration is a good starting point. To involve personnel and the trade unions in the planning is essential for a successful merger. Aviation is guided by a very strong international regulatory framework which has to be followed in detail. To have the operations manuals and the procedures ready before the merger is not only mandatory, it also gives a smoother process. As the merger is a process with many challenges for all involved it is recommendable to plan for more personnel rather than fewer personnel during the initiation of the project, thus an extensive staffing. Last but not least to have the agreements between management and the trade unions on salaries, pensions, holidays and working conditions ready before the merger gives a smoother process. If that is not the case too much time will be spent on fighting each other. The great number of trade unions, 14 in this case, makes this process a delicate matter. This merger is successful and shows that it is possible to learn from each other's cultures although adequate time has to be given for the process.

\section{Work domains comparison}

\section{Work task and environment}

Both controllers and pilots have highly specialized tasks. Based on many years of research with both controllers and pilots it is our meaning that these two groups share an awareness of the great responsibility involved in their high risk work and the fact that they lack control over events and processes contribute to risk and increase the need for timely and relevant information and support both for planning and real-time operations. They work in shift with varying sleep patterns. Another commonality would be possible high mental workload in terms of information processing with perception, attention, decision making and problem solving. 
Air traffic controllers maintain the safe and orderly movement of aircraft along major air routes and around airports by giving pilots instructions and advice as to height, speed and course. The majority of controllers work at control centres as area controllers responsible for keeping aircraft flying the airways. Others work as approach controllers dealing with aircraft movement into and out of an airport, or aerodrome controllers guiding through landing and to the terminal.

Pilots have several flight phases and contact with ATC during pre-flight, flight execution and post flight. Pilots have irregular working hours, no fixed work team that you always work together with, rare communication among a large group and with leaders or managers.

\section{Technology for pilots and controllers}

In the very beginning air traffic was separated visually by pilots adhering to simple rules of traffic. Since the emergence of radar technology the responsibility for separating air traffic has been on ground based ATC. The operative work of assuring separation between aircraft has been carried out by air traffic controllers through watching radar screens and upholding communication with pilots over radio. As a means to managing controller workload the air space has been divided in ATC sectors, where every sector has its own controller who is responsible for the separation of traffic. Every time an airplane enters a new sector and is transferred to a new controller, the pilot has to manually change to a different radio frequency to be able to talk to the controller of the new sector (Barchéus and Mårtensson, 2007).

Presently ATC performs separation assurance using radar surveillance and analogue radio communication. In the emerging environment this will be substituted by Automatic Dependent Surveillance-Broadcast, ADS-B, and Controller Pilot Data Link Communication, CPDLC.

ADS-B is a data link application that transmits surveillance data such as position and identification from aircraft and vehicles to other users in the vicinity. It is anticipated that ADS-B will provide many benefits - from extending the range and coverage of current ground-based secondary surveillance radar (especially around airport surfaces) to increasing air-to-air situational awareness (Prinzo, 2004).

\section{Process and cooperation}

The controllers are locally stationed and interact with pilots during their whole work process from airplanes passing their sector or land and take-off at their airport. Pilots interact with different controllers during pre-flight, during active flight process and during approach and landing. The context for pilots and controllers work is very different, yet they are complementary actors in a joint cognitive sys- 
tem (Hollnagel, 2007) with overlapping functional causal system. The general opinion on the cooperation between controllers and pilots is that it is overall good and that there is trust between the two groups (Barchéus and Mårtensson, 2007). Pilots are responsible for the safe flight of the passengers and to the company for keeping flight costs down and are often anxious to land as soon as possible without extra delays in flight. The controller is responsible for the safety of several airplanes and has to create a steady flow of traffic, and may occasionally have to take decisions that are not optimal for single airplanes, a situation which may lead to a less understanding attitude from pilots. In the presented study, controllers stated that they would agree to hand over the responsibility for separation to the pilot, but if the pilot wants to return the responsibility the controller may already be fully occupied. Having the responsibility the whole time means you can manage the workload in a better way. To quote one if the interviewed controllers: "It is still 'us' and 'them'. The pilots only have their aircraft. We have everything" (Barchéus and Mårtensson, 2007).

\section{Team}

In commercial airplanes there are two pilots in a flight crew, one captain and one co-pilot. The flying crew works with the cabin crew as well. Pilots seldom work with the same pilot or cabin crew. The team varies from flight to flight. An airline like SAS has around 2000 pilots.

In ATC there are two controllers for each sector, one executive and one planner. The executive is working with the current air traffic flow and the planner has supervision over the traffic entering the sector and plans the work in order to facilitate for the executive (Eurocat 2000E, as cited in Arvidsson, 2006). Controllers interact with colleagues on a daily or weekly basis in both towers and at control centers. For example Arlanda ATCC has 250 persons.

\section{Procedures}

Both controllers and pilots follow standard operations procedures (SOP). There is not much room besides pre-defined phraseology between communication between air and ground, between pilots and controllers, or within controller's team or flight crews in their routine work. On longer cruises in normal flight pilots will have periods of lower work load, which may give opportunity to casual conversations with the rest of the crew. Controllers have more of a continuous work load when on duty but it is normal to have a schedule with one hour on duty and then 30 minutes break. They are given opportunities for social interaction during their scheduled breaks. The aviation community uses a strict phraseology in order to in- 
crease intelligibility over noisy radio frequencies (Barchéus and Mårtensson, 2007).

\section{Reporting}

Reporting is part of a standard routine in case of events which may have effect on safety. Results from both ATC (Arvidsson, 2006) and FO (Ulfvengren, 2007 a) research show that operators still think it is too difficult or inconvenient to file reports.

In a reporting study from flight operations the main reasons for not reporting were concluded to be (Ulfvengren, 2007 a) due to organisational issues such as lack of relevant feedback, lack of change initiatives accordingly and environmental factors such as access to tools, time and effort to file reports. Results points at the need to enable more direct feedback from those responsible for the reported issue, to trace issues reported in the organisation, to allocate more resources for departments to handle reports and give feedback as well as to show system changes and improvements based on reports. The reporting tools needs to be easily accessible on-board and user-friendly to save time and effort to write them.

\section{The future system}

Changing the technology, that is supporting the pilots and the controllers, will also change their routines and work content. Attitudes and apprehensions towards these changes are important and may affect the outcome of the operation. Some examples of the more pertinent changes, which may be positive as well as negative, are: The shift of responsibility between pilots and air traffic controllers; New ways to communicate, e.g. data link that will possibly reduce mishearing and misunderstanding due to low audio quality or language skills; Shared information may or may not improve conditions for decision making between the two groups.

In present Air Traffic Control, communication between pilots and controllers is managed using analogue radio technology, thus radio transferred speech is the main mean of communication between pilots and air traffic controllers. Although being a simple and common way of communication, sound quality and language issues often create obstructions for the users and previous research has shown that much of the communication is not acknowledged properly (Rantanen and Kokayeff, 2002). With future data link communication, voice will still be used because of its effortless input and flexibility. Although CPDLC is emerging, voice will remain for a foreseeable future. This is a large change in technology and although voice may be regarded an error prone mean of communication, mainly because of language deficiencies and sound quality, the shared radio frequencies enable pilots to create a situational model based on communication between other 
parties in the vicinity, generally referred to as Party Line Information (Midkiff and Hansman, 1993).

Enabled by ADS-B pilots will be provided with traffic information in the cockpit, which will consequently lead to a shift in information symmetry. At present the controller is the sole keeper of accurate visual traffic information. The currently very clear division of labour between pilots and controllers may be fundamentally changed with the introduction of Cockpit Displays of Traffic Information, CDTI, although responsibility for separation will initially remain with ATC. The provision of information to the flight crew means that pilots can question controller decisions based on their own traffic picture. This may in turn interfere with controller intentions and might result in increased workload and stress for controllers (Barchéus and Mårtensson, 2007).

\section{Discussion}

The examples of research presented here in many ways support the idea of combining system, action, sense-making and culture into a new Human Factors model and that these terms relate to different aspects of the same underlying reality. Assessing culture is useful in identifying weaknesses which may emerge to have impact on safety or to identify essential areas for successful implantation of major organisational changes. In another field of research, innovation, Bessant (2003) has developed a reference model for continuous innovation and organisational learning which lists organisational abilities and examples of constituent behaviours. Relevant to this discussion is behaviours like; People use appropriate tools and techniques to support the work. People use measurement to shape the improvement process. The ability to link continuous improvement activities to the strategic goals of the company. Managers support the process through allocation of time, money, space and other resources. Managers recognise in formal ways the contribution of employees. People co-operate across internal divisions (e.g. crossfunctional groups) as well as working in their own areas. People understand and share a holistic view (process understanding and ownership).

In Bessant's (2003) research, one conclusion was that it is not so much what tools that are used that determine a success but the main issue is the continuous innovation behaviour. Nevertheless tools and methods are required to acquire human factors related information from the operators, and to facilitate necessary communication processes for information handling and reporting culture. Just like in the reporting study attitudes and behaviour in reporting will not be improved by reminders, seminars or training, alone. Resources, structures and tools must fit the real operations as well.

With the strong professional cultures it is reasonable to assume also pilots and controllers are well-intended people just as the maintenance people. It is for other reasons there is a mismatch between the view of management providing for support, resources tools and time and the view of the people in operations receiving 
the same. They make sense of different contexts and work. The concrete result is perhaps mutual lack of trust and the sense of a strong need for more and better information, communication and participation.

The idea is that the HILAS project will support much of these aspects. In HILAS the tools (organisational and technical) were all developed with an overall process framework of strategic, tactical and operational management in mind. For example for reporting tools it meant having both top-down as well as bottom-up requirements for information and feedback as well as related change processes to prove reporting effective and meaningful. The HILAS system also considers individuals as well as system input and feedback on risk and performance management, which is balancing support and control.

As mentioned the OPM/KSM is a process modelling and analysis tool but also a methodology for a knowledge (both tacit and explicit) transformation process. This process facilitates creating a common view of the system processes as well as cross-learning. This in turn may foster a more homogenous culture which will strengthen the change mechanisms.

The HILAS approach is relevant to the fragmented system and possible merges of ATCCs across Europe. But many of these issues discussed could be applied also to developing future technology and collaborations between the pilots and the controllers.

The human effects of this paradigm change in the air will include new roles and responsibilities for pilots and air traffic controllers, new ways of cooperation, new training, procedures, phraseology, safety issues, system complexity just to mention a few. Consequently, all aviation stakeholders will face major challenges, not only technical but also societal, cultural, organizational and personal ones. The future change is of great concern, one controller expressed considering the future: "I am pleased to say that I will be retired by the time new technology will be introduced".

So far the technological change itself, but which are the potential barriers for introducing new technology? The development has been lead by the air traffic management community with minor participation of the airlines. Although air traffic controllers and pilots are completely dependent on each other in their daily work, minute by minute, there seems to be much little cooperation "off-duty". Controllers and pilots have very different background, education, working conditions and careers. Despite different professional culture they have much in common too.

Further research should be focused on discussing the relevance for developing a common process model with training modules for cross-learning and develop a common reporting system to feed common risk models and performance measures.

The same as for the overall aviation system should apply to this particular system consisting of two sets of complementary functional processes. The overall implication for future work design between controllers and pilots is not only cultural. It is necessary to "Develop theoretically sound practice that can create new organisational processes which are functionally effective for all stakeholders and 
which then provide the basis for a new collective understanding of how the system can work”(McDonald, 2009) and go from there.

Acknowledgments The authors would like to thank all of the HILAS team and especially the APRG at TCD for all the great work and great fun!

\section{References}

Arvidsson, M. (2006) Organizational Psychology and Safety Culture in Air Traffic Control. Doctoral thesis at Lund University. ISBN 13: 978-91-628-6903-8, Lund, Sweden.

Barchéus, F., Mårtensson, L. (2003). New Air traffic Management systems - views of Air traffic controllers. Preprints of the $8^{\text {th }}$ IFAC/IFIP/IFORS/IEA Symposium on Automated Systems Based on Human Skill and Knowledge, September 22-24, 2003, Chalmers, Göteborg, Sweden,

Barchéus, F., Mårtensson, L. (2007). Air traffic management and future technology - the views of the controllers. Human Factors and Aerospace Safety - an International Journal 6(1), 116. Ashgate Publishing Ltd

Bonnier, M. (2004). DOVE-2 Model Based Simulation (EEC Report 389). Brétigny-sur-Orge: EUROCONTROL Experimental Centre

Conroy, P., Deransy, R., McGregor, R., Pichancourt, I., Whiteley, M. (2002). LINK2000+ Realtime simulation project (EEC Report 376). Brétigny-sur-Orge: EUROCONTROL Experimental Centre

Conroy, P. (2003). DOVE 1 Fast-time simulation (EEC Report 381). Brétigny-sur-Orge: EUROCONTROL Experimental Centre

Díaz-Cabrera, D., Ramos-Sapena, Y., Hernández-Fernaud, E., Casenave, S. (2009). Culture and the implementation of Knowledge Management Systems (KMS). HILAS report, deliverable and draft manuscript to book in preparation. Project Number 516181. Funded by European Commission - Sixth Framework Programme.

Eurocontrol (1998). Air traffic management strategy for 2000+.

European commission (1999). The creation of the single European sky. Brussels, European Commission.

Hopkin, V.D. (1995). Human factors in air traffic control. London: Taylor and Francis

Hollnagel, E. (2007). Flight decks and free flight: Where are the system boundaries? Applied Ergonomics 38(4): 409-416.

http://www.prospects.ac.uk, 2010.

McDonald, N., Cromie, S., Ward, M. (1997): The impact of safety training on safety climate and attitudes. In Aviation Safety (Editor Hans Soekkha) Utrecht: VSP, pp 649-660.

McDonald N. (ed.) (1999). Human-centred management for aircraft maintenance ADAMSWP4A-D2 (April 1999). Deliverable report to the European Commission from the ADAMS project. Department of Psychology, Trinity College Dublin

McDonald N. (2001). Human systems and aircraft maintenance. Air and Space Europe, 3 (3/4), 221-224.

McDonald, N. (2001). The development and evaluation of SCARF. Paper presented at 'Managing the risk of the flight-ground safety interface' conference. Australian Aviation Psychology Association, Melbourne, Oct 2001.

McDonald N., Corrigan S., Cromie S., Daly C. (2000). Safety management systems and safety culture in aviation maintenance organisations. Safety Science, 34, 151-176.

McDonald, N. (2006). Human Integration in the Lifecycle of Aviation Systems, HILAS project internal report. Project Number 516181. Funded by European Commission - Sixth Framework Programme. 
McDonald, N. (2010, in prep.). Transformation: Human Factors and Organisational Change. HILAS report, deliverable and draft manuscript to book. Project Number 516181. Funded by European Commission - Sixth Framework Programme.

McDonald, N., Ulfvengren, P., Ward, M. (Editors) (2010, in prep.). Change, HILAS deliverable and draft manuscript to book. Project Number 516181. Funded by European Commission Sixth Framework Programme.

Midkiff, A. H., Hansman, R. J. (1993). Identification of Important "Party Line" Information Elements and the Implications for Situational Awareness in the Datalink Environment. Air Traffic Control Quarterly, 1, 5-30.

Prinzo, O.V. (2004). Automatic Dependent Surveillance - Broadcast/Cockpit Display of Traffic Information: Innovations in Pilot-Managed Departures. The International Journal of Aviation Psychology, 14, 171-189.

Rantanen, E.M., Kokayeff, N.K. (2002). Pilot errors in copying air traffic control clearances. Proceedings of the 46th Annual Meeting of the Human Factors and Ergonomics Society, 145149, Santa Monica, CA: Human Factors and Ergonomics Society.

Reason, J. (1997). Managing the risks of organizational accidents. Ashgate Publ. Ltd: Aldershot, UK.

SESAR-consortium (2008). D5: SESAR Master Plan.

Ulfvengren, P. (2007 a). Study on how to increase reporting in aviation. In proceedings of Nordic Ergonomic Society, NES 2007.

Ulfvengren, P. (2007 b). HILAS tools for continuous improvement in aviation? In proceedings of CINet, Continuous Innovation network conference, Gothenburg, 2007.

Ulfvengren, P., Rignér, J., Mårtensson, L. (2009 a). Integrating safety and innovation in aviation. In proceedings of International Ergonomics Association, IEA 2009, Bejing, China.

Ulfvengren P., Rignér J., Ydalus M., Mårtensson L. (2009 b). SAS HILAS Participation and Experiences. HILAS report, deliverable and draft manuscript to book in preparation. Project Number 516181. Funded by European Commission - Sixth Framework Programme. 